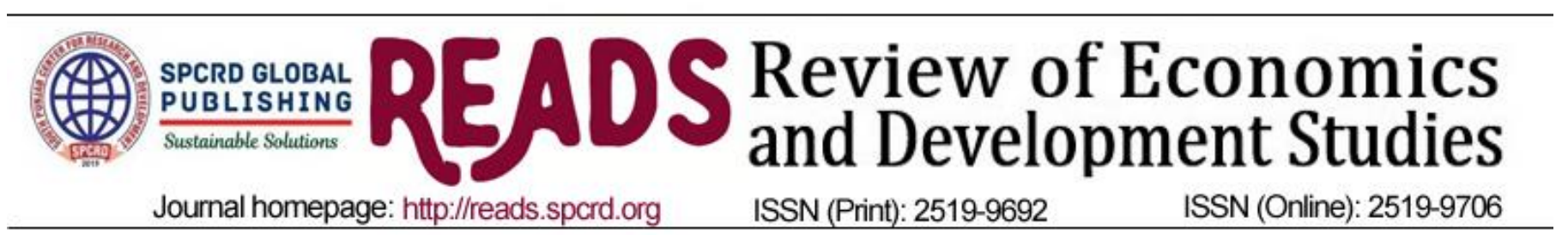

\title{
Nexuses between Malnutrition, Social Exclusion of Children and Human Capital: A Qualitative Study
}

\author{
${ }^{\text {a }}$ Uzma Niaz, ${ }^{\text {b Nazia Malik, }}{ }^{\mathrm{c}}$ Sadaf Mahmood, ${ }^{\mathrm{d}}$ Zahira Batool \\ ${ }^{\text {a }}$ PhD Scholar in Sociology, Department of Sociology, GC University Faisalabad, Pakistan \\ Email: Uzmaniaz36o@gmil.com \\ ${ }^{\mathrm{b}}$ Assistant Professor, Department of Sociology, GC University Faisalabad, Pakistan \\ Email: naaziamalik@gmail.com \\ ${ }^{c}$ Assistant Professor, Department of Sociology, GC University Faisalabad, Pakistan \\ Email: sadaf.mahmood88@yahoo.com \\ ${ }^{\mathrm{d}}$ Professor, Department of Sociology, GC University Faisalabad, Pakistan \\ Email: batoolazam@hotmail.com
}

\begin{tabular}{ll}
\hline ARTICLE DETAILS & ABSTRACT \\
\hline History: & The present study describes the parents' attitude towards malnutrition, \\
Accepted: 22 May 2020 & social exclusion of children, and human capital in three districts of South \\
Available Online: 15 June 2020 & Punjab, Pakistan. The qualitative research approach is applied with three \\
& Focus Group Discussions (FGDs) with parents of children. The interview \\
& guide was used to collect data and thematic analysis approach was done. \\
Keywords: & It was concluded that malnutrition made the children socially excluded \\
Malnutrition, Social Exclusion, & by damaging their health, academic achievements, and losing their \\
Children, Human Capital, & interests in games. It was also concluded that no education and skills of \\
Education, Skills & malnourished children become socially excluded from their workplaces. \\
& Finally, it was concluded that this situation of malnutrition leads them \\
JEL Classification: & toward social exclusion. Therefore, this social capital of the future in the \\
I12, O17, E24 & shape of social exclusion of children increases the economic burden of \\
\hline & family and ultimately nation. To overcome this issue, steps should be \\
DOI: 10.47067/reads.v6i2.209 & taken by the government and community level.
\end{tabular}

(C) 2020 The authors. Published by SPCRD Global Publishing. This is an open access article under the Creative Commons Attribution-

NonCommercial 4.0

Corresponding author's email address: Uzmaniaz36o@gmil.com

\section{Introduction}

It is a common perception for the majority of people that capital means money, shares in the stock market, and production plants. But actually, all these are the forms of capital and termed as assets that yield income. Training, schooling, expenditures on medication, lectures on regularity, honesty, and punctuality are also forms of capital. All these forms help to uplift the health, improve the earning and interpolate to an individual's good habits throughout his life. Consequently, experts regard the expense of training, education, and health care as an investment in human capital. According to these experts, 


\section{Review of Economics and Development Studies, Vol. 6 (2) 2020, 315-322}

knowledge, skills, and health quality of the people are the human potential of as in the way as their financial and physical assets because the training, education, and health are the most central investments in human capital.

Like other developing countries, Pakistan retains its focus on 2030 Agenda of Sustainable Development Goals and trying to adopt and implement all Seventeen Sustainable Development Goals (17-SDGs) according to actual philosophy. Three goals (1, 3, and 5) out of seventeen indicate the brighter future of the children throughout the world by giving the rights to the child. The Sustainable Development Goals (SDGs) are determined worldwide plan of action for all communities, prosperity of the world, and the planet which stands for well-being and rights of every child (boy and girl). The Sustainable Development Goals (SDGs) give the assurance of equity-based assurance to 'leave no one behind'. To achieve the Sustainable Development Goals (SDGs), and develop the human capital it needs to compete nationally and internationally, upholding the rights of every boy and girl and ensuring that no child is left behind is a vital pre-condition for Pakistan in the 21st century.

Malnutrition remains a serious public health issue around the underdeveloped countries, especially in South Asian and African countries. Mostly malnourished children are present in developing and poor countries. Ergin (2007) explained that 70\% of malnourished belong to Asia, 26\% to Africa, and $4 \%$ to Latin America. Grover (2009) explained that a study done in 53 countries explored that over $50 \%$ of deaths of the children are related to under-nutrition. Malnutrition can be delineated in multiple ways. Child malnutrition is a pathological condition caused by insufficient nutrition; malnutrition contains three broad concepts which can be described as under-nutrition, over-nutrition, and micronutrient deficiency. Grover (2009) described that malnutrition is a physical condition of inadequacy or superfluity of protein, energy, and different other nutrients. Malnutrition is the outcome of insufficient food supply which is caused by social, economic, political, and sometimes environmental factors like a natural disaster, as explained by Shah (2003) that the major threats for stunting are female education ignorance, the poor economy of the household and overcrowding.

Malnutrition is consociate with brain functional and structural pathology. Many cognitive problems have been related to poorly nourished children. Wasting and Stunting caused by chronic protein-energy malnutrition (PEM) could have a continuous effect on the development process of cognition during childhood ( $>5$ years of age). In poor societies, malnutrition is the best lookout as a "syndrome of developmental impairment," this includes growth retardation, slow down cognitive skills and the process of behavioral development; diminished capacity for a normal immune response; and raised morbidity and mortality (Martorell, 1999). Malnutrition is the earliest reason for immunodeficiency around the world, and mostly affects infants and children as well as adolescents and elders (Peter, 2008).

Dangour (2013) depicted that in the year 2000, it has been reported that over 200 million school-age children were found to be stunted said by the United nation for children's funds. In this report, it is also marked out that if no serious effort is done to control this rate the proportion will reach up to 1 billion in 2020 .

Room (1995), talked in the research regarding violation of the fundamental rights such as civil rights, social rights, and political rights as a citizen. A right-based approach in America was the model of inclusion of common people to engage them in common decisions under the umbrella of the inclusion movement. This inclusion movement was much common as Sen (1992) called expressed its capability approach. 


\section{Review of Economics and Development Studies, Vol. 6 (2) 2020, 315-322}

The philosophy behind this call was that all the people have equal access to necessities like the health of the people, food for the people, the roof for the people, and the right to enjoy the social life.

Child growth is considered as a significant index to check the nutritional level and health status in populations. Stunting is recognized as the most significant indicator of child growth. Thinness low body mass index is known as wasting. Stunting comes from the less availability of food and nutritional ingredients, lack of childcare, and poor social and cultural environment. Stunting consociate with high morbidity and mortality rate reduced mental and intellectual capacity and poor academic performance. Stunting is known as the best indicator to predict social progress. Child under-nutrition is considered a substantial indicator of diseases caused the millions of deaths of children and heavily increased the health expenditures in developing countries (Mushtaq, 2011).

In Pakistan, Section 2 (a) expresses the definition of the child, a child means a person who is under 18 years for male and it is less than sixteen years of age for a female. But according to The West Pakistan Vaccination Ordinance 1958 Section: (a) "child" means a person who has not completed the age of 16 years. The United Nations Convention on the Rights of the Child (UNCRC) defines a child as "a human being below the age of 18 years unless under the law applicable to the child while in U.S. Immigration Law, a child refers to anyone who is under the age of 21.

According to the paper published by Sen (1992), Social exclusion can be defined as "the inability to participate in, and be recognized by, society. A rich edition would also add the terminologies of such recognition, appreciation, and participation in the definition. Specifically, recognition by the people by society and participation in society has to be on the terminologies of equality or equal opportunity. It would make sure equal opportunity inbuilt among the civic rights as citizenship and the protection of individual self-esteem and dignity are essential to establish the balance in all societies to make social interactions strong and long.

A famous Scottish philosopher and economist Adam Smith introduced the concept of human capital back in the 18th century. He defined the human capital that "human capital" is the cluster of individuals, commonly called workforce who work for or are qualified to work for the society or an organization" in its most basic sense. On the other hand, the different factors needed to create a sufficient supply of available labor form the basis of human capital theory and are critical to the economic and social health of the world's nations, in a larger sense. Human Capital is the summation of education and knowledge, skills, abilities, and social traits that add to the individual's capability to carry out the task in a way that creates the financial worth.

Malnutrition and health are closely interlinked with each other. Malnutrition directly affects health. Malnutrition puts the burden on the children in the form of different diseases. Diseases and poor health status almost affect all the areas of the developmental process as well as creates problems throughout life. The physical and mental health of early life gives the basis for adult life. Because the process of development mostly occurs in the early years of life so we discuss the three major areas of the lives of the children which are might be affected by malnutrition namely school performance, socialization process, and economy. There are many other factors like poverty, low parental education, social and gender discrimination, racism, political and environmental conditions and less availability of resources that hinder the school performance, damaging the economy and reducing the social activities; but despite that, these three aspects might be affected by malnutrition because better nutrition is considered the basic to proper human development and better health conditions. Today the health 


\section{Review of Economics and Development Studies, Vol. 6 (2) 2020, 315-322}

condition of millions of people all over the world is entirely discouraging, specifically in underdeveloped countries. Ergin (2007) depicted that malnourished children had lower resistance to infectious diseases and they die early. He was of the view that the children who survive face the problems of growth retardation, illness, and poor nutritional levels which keep the malnourished children into a dreadful recurring cycle of sickness and this hindered the learning ability of the children.

The malnutrition has a lot of significance in the present time due to its worst and long-lasting impacts on the lives of the children. In the present study, it was discussed how malnutrition reduces the potential of the children which makes them excluded from the mainstream. This exclusion of children is putting the burden on the families at one side and damage the human capital of the country on the other side simultaneously. Children are the future of every nation and can play a vital role in the economy as the productive human capital of that country if this nursery becomes skillful and educated. Provision of better nutrition to the children can include them in the productive layer of the economy of any country and ultimately, they can prove themselves as human capital for the nation as well. The overall objective of the study is "to explore parent's attitude towards the relationship between Malnutrition, Social Exclusion of Children, and Human Capital.

\section{Review of Relevant Literature}

Mahoney (1997) studied the connection between participation in extracurricular activities and the early dropout of the students from the school. The findings of the study explored that participation in extracurricular activities lowers the dropout rate of the students.

Norgan (2000) stated that growth-retarded children most probably had fewer job and promotion opportunities, low productivity as an adult, more prone to diseases, and higher mortality risk in adulthood.

Alaimo (2001) demonstrated that mostly food secure children probably had repeated their class, terminated from the school, and also showed lower performance in arithmetic scores. Further, foodsecure children probably need a psychologist because they have psychosocial problems and face problems to live with other kids.

Patacchini (2008) explored that weak social ties create more opportunities for the delinquents to contact non-delinquents and this weakness in social relationships induce more the non-delinquents towards criminal activities.

Rena (2010) analyzed that in the international market of human capital educational quality have the much importance. He said new opportunities were captured by some developing countries got more benefits. Education plays a very important role in economic growth because human capital development and economic growth were essential to each other especially (Ranis, 2011).

Crookston (2011) stated that under-nutrition delays the children's entry into school lessens the years of schooling affects the height of the children and also reduced productivity as an adult.

Paul (2012) the research examined the association between the unbalanced meal program and academic performance of the learners. He took a sample of 300 students from both rural and urban areas. He considered the four factors of academic performance (retention, attendance, enrollment, and drop out of the students) to find out the association between academic achievement and an unbalanced meal program. The study displayed that an unbalanced meal program positively influenced the 


\section{Review of Economics and Development Studies, Vol. 6 (2) 2020, 315-322}

academic performance of the students by taking into account the four factors; retention, attendance, enrollment, and drop out of the students. Furthermore, the unbalanced meal program enhanced the enrollment and attendance of the students also lowered the dropout and retention rate of the students. This program is also helpful to remove hunger from the classroom, to improve social and gender equity, and in the development of some good habits among the students like washing the hands before the meal in the school.

Freijer (2013) explained that disease-related malnutrition has serious consequences for physical health and also creates psychosocial problems. He studied the additional costs related to diseases related to malnutrition and argued that the additional costs to manage the patient of diseases related to malnutrition were considerably higher than other patients.

Chinyoka (2014) found that malnutrition affects all the areas of physical growth and mental development of the child including school performance. The results of the study demonstrate that the undernourished and hungry children are less capable to attend the school and if attend then facing the problems in concentrating and learning, also having no interest to take part in physical activities and sports event. Malnutrition also leads to poverty because malnutrition increases health expenditures due to its worst impacts on health.

Romaisa (2016) explored the relationship between human capital formation and poverty reduction with a special focus on the education and health sectors. So, she took infant mortality rate and health expenditures as health indicators on the other hand educational status detained with literacy rate and enrollment in higher education during the time period of 1973-2013. She concluded with the results that in Pakistan, there is dire need to invest capital at a huge level in education and health sectors to make the children healthy and productive as human capital. This is the only way to make policies to mitigate poverty.

To be trained with new skills to meet job demands is the direct connection between human capital development and planned activity for human capital. Learning with necessary skills is the cure to all Human Resource Development (HRD) efforts. Consequently, all researchers focused on education, training, and skill development to increase performance. Presently, HRD mainly focuses to develop people's knowledge, expertise, productivity and satisfaction for development of his personality, community and nationwide for whole humanity (Berg, 2016).

Khan (2019) tried to measure the impact of education and health sectors to eliminate poverty through the development of human capital. In this study, to measure the Human Capital, researchers have employed two proxy variables i.e. life expectancy and education expenditure. The controlled variables in the study are capital formation, labor force, agriculture, manufacturing value-added, and inflation. The fixed effect and random effect models are used in this study. Results show that human capital variables are found significant. Therefore, this contributes as an engine for development, growth, and job opportunities in developing countries. DATA AND METHODOLOGY

The purpose of this study is to evaluate the nexuses between Malnutrition, Social Exclusion of Children, and Human Capital. This study was conducted in Punjab Province, Pakistan. By using convenient sampling techniques three districts namely Multan, Lodhran, and Muzaffargarh of South Punjab were selected out of thirty eleven districts. The children ranging from the ages of 10-15 years working at auto workshops were the targeted population. The study carried out by using a mixedmethods research approach through qualitative and quantitative research studies. This article is based on a qualitative research approach and this part was carried out by the parents of excluded children 


\section{Review of Economics and Development Studies, Vol. 6 (2) 2020, 315-322}

working on auto workshops with a specific age between 10 to 15 years. The minimum age for admission to work for a child is 15 years under Punjab Restriction on Employment of Children Ordinance 2016. The qualitative research approach was applied through the Focus Group Discussions approach by taking the information through Focus Group Discussion guide. Total o3 Focus Group Discussions (FGDs) were conducted (one FGD in each district) with parents of the children working at the auto workshop. Qualitative data analyzed through transcribing the data and identification of themes for interpretation.

\section{Results and Discussions}

The following results are extracted from the analysis of Focus Group Discussions with the parents of the excluded children working at the auto workshop.

\subsection{Malnutrition, School Performance and Social Exclusion Of Children}

The participants gave a clear view that malnourished children mostly show the low output to homework regular because of physical deficiency and also show little interest in co-curricular activities. This situation directs them to social exclusion.

\subsection{Malnutrition, Low Skills and Social Exclusion of Children}

Children suffering from malnutrition attain low grades in schools so their parents kept them from schools and put them at auto workshops for earning. But response during a discussion with the owners of auto workshops indicated that these children cannot show their interest in the work there too. Due to lack of interest, they are beaten by the seniors/owners and this leads to an inferiority complex and they want to live alone.

\subsection{Malnutrition, Social Exclusion and Human Capital}

When the parents probed towards the role of children as human capital for the development of the country, they become upset and give their clear expression towards futuristic damage to the nation. They consented that due to malnutrition, their children become socially excluded and they cannot enjoy their basic rights like education health and skills. Participants unanimously replied that the malnourished situation of their children does affect the human capital of the country.

\section{Discussions}

The children who bear malnutrition in early life can face many functional problems in later ages of life. Malnourished children face many health issues and mostly suffered from diseases. Diseases and other health problems put the burden on the economy of the household as well as on the economy of the nation. On the other hand, malnourished children remained poor performers in school, and ultimately they quiet. Parents cannot bear these children and put them into auto workshops to earn some money. Due to malnourishment, they are less productive because they have low capacity to do any kind of work; ultimately they face a lot of issues at the workplace and adopt different bad habits like smoking, drug addiction, and theft/robbery. These results of the focus group discussion are found very close to the study of Chinyoka (2014) depicted that malnutrition also leads to poverty because malnutrition increased health expenditures due to its worst impacts on health. Martorell (1999) stated that malnutrition lowers the intellectual performance, lowers the productivity level, and also lowers the work capacity. The better nutrition and food most probably will produce more healthy and productive adults, which in turn increased the human capital and economy.

\section{Conclusion}

Malnutrition can be turned around into a vicious cycle with the social exclusion of children due to its adverse impacts on human capital. Malnutrition of excluded children affects the human 


\section{Review of Economics and Development Studies, Vol. 6 (2) 2020, 315-322}

capital in two ways. First, malnutrition leads to health problems (diseases) of the children and they remained alone and separate from others due to illness. Moreover, malnourishment of children disturbs the school performance of such children and they quiet the school and ultimately they become excluded. Secondly, these children are thrown into auto workshops to earn some money to cater to the economy of the household. But these children cannot perform better in their workplace too, so they become excluded. The above conclusion indicated that these excluded children become the burden due to malnourishment on the household and nation in the future. In short, this nursery which should be the asset as human capital in the future for the country, become the liability on the family as well as on the nation.

\section{Recommendations}

Based on discussion and conclusions, it was suggested that awareness campaigns and workshops should $b$ rearranged for the parents to upgrade their knowledge about the importance of health and damage done by the malnutrition of children. Community-based health engagement services of malnutrition must be integrated to improve the immunity level of the children. Malnutrition should be included in the mainstream development framework health structure. Community-based social and physical activities must be planned and encouraged. There should be compulsory, training programs for teachers and students regarding malnutrition at the school level.

\section{References}

Arif, R., Faridi, M. Z. and Farooq, F. (2016). The Role of Human Capital Formation in Poverty Mitigation: A Co-integration Analysis from Pakistan. Review of Economics and Development Studies, 2 (2) 129-138

Alaimo K., Olson C.M., \& Frongillo E.A., Jr. (2001). Food Insufficiency and American School-Aged Children's Cognitive, Academic, and Psychosocial Development. Pediatrics.

Broh B.A. (2002). Linking Extracurricular Programming to Academic Achievement: Who Benefits and Why?. Sociology of Education. 75(1), 69-95. Published by: American Sociological Association Stable URL:

Chinyoka K., (2014). Impact of Poor Nutrition on the Academic Performance of Grade Seven learners: A Case of Zimbabwe. International Journal of Learning \& Development, 4(3), ISSN 2164-4063.

Crookston, B.T., Dearden, K.A., Alder, S.C., Porucznik, C.A., \& Stanford, J. (2011). Impact of early and concurrent stunting on cognition. Maternal \& Child Nutrition, 7(4), 397-409.

Dangour, A. D., \& Uauy, R. (2013). Nutrition challenges for the twenty first century. 2006. Accessed in December.

Grover Z., Ee L.C. (2009). Protein Energy Malnutrition. Pediatric Clinics of North America, 56 (5), $1055-1068$.

Ergin F, Okyay P, \& Atasoylu G, Beşer E. (2007). Nutritional status and risk factors of chronic malnutrition in children under five years of age in Aydın, a western city of Turkey.

Hirani, S. A. A. (2012). Malnutrition in young Pakistani children. Journal of Ayub Medical College, 24(2), 150.

Khan, R. and Chaudhry, I. S. (2019). Impact of Human Capital on Employment and Economic Growth in Developing Countries. Review of Economics and Development Studies, 5 (3), 487-496

Mahoney J.L., Cairns R.B. (1997). Do Extracurricular Activities Protect Against Early School Dropout?. Developmental Psychology. 33(2), 241-253.

Martorell R. (1999). The nature of child malnutrition and its long-term implications. Food and Nutrition Bulletin, 20 (3). The United Nations University.

National Economic Survey (2007). Government of Pakistan, Economy of Pakistan (2006-7), Islamabad: 
Pakistan;

Norgan N. G. (2000). Long-term physiological and economic consequences of growth retardation in children and adolescents. Proceedings of the Nutrition Society, 59, 245-256.

Ranis, G. (2011). Technology and Human Development. Economic Growth Center Yale University.

Shah S.M., Selwyn B.J., Luby S., Merchant A., \& Bano R. (2003). Prevalence And Correlates Of Stunting Among Children In Rural Pakistan. Pediatrics International, 45(1), 49-53.

Van den Berg, H. (2016). Economic growth and development. World Scientific Publishing Company. 